\title{
Tendência à hidratação do pó de alumínio em concretos refratários contendo elevado teor de carbono
}

\section{(Hydration of aluminum powder in high-carbon containing refractory castables)}

\author{
V. G. Domiciano, I. R. de Oliveira, V. C. Pandolfelli \\ Departamento de Engenharia de Materiais - DEMa \\ Universidade Federal de S. Carlos \\ Rod. Washington Luiz, km 235, C.P. 676, S. Carlos, SP 13565-905 \\ g176710@polvo.ufscar.br,vicpando@power.ufscar.br
}

\begin{abstract}
Resumo
Os benefícios proporcionados pela adição de carbono em concretos refratários têm ampliado a utilização desses materiais em aplicações siderúrgicas. Contudo, um problema inerente à utilização de carbono em refratários é a sua susceptibilidade à oxidação a temperaturas superiores a $600{ }^{\circ} \mathrm{C}$. Uma das alternativas empregada na tentativa de controlar a oxidação do carbono é o uso de antioxidantes. Dentre eles, o pó de alumínio tem mostrado bons resultados em tijolos refratários contendo carbono. Porém, sua aplicação em concretos refratários é limitada pela forte tendência que o pó de alumínio apresenta em se hidratar. Algumas técnicas de recobrimento baseadas no processo Sol-Gel têm sido empregadas como forma de impedir a reação de hidratação do pó de alumínio quando em água. Entretanto, a eficiência destes recobrimentos ainda não foi avaliada em concretos refratários. O presente trabalho se propõe a avaliar a eficiência de recobrimentos à base de $\mathrm{SiO}_{2}$ ou $\mathrm{TiO}_{2}$ em inibir a reação de hidratação do pó de alumínio em condições reais de aplicação. Estes recobrimentos foram obtidos a partir de alcóxidos metálicos e um polímero reativo fazendo uso do método Sol-Gel.

Palavras-chave: concreto refratário, carbono, pó de alumínio, hidratação, recobrimento.
\end{abstract}

Abstract

The benefits promoted by the addition of carbon in refractory castables resulted the increase use of these materials in steel making industry. Nevertheless, carbon-containing refractory castables faces the problem of oxidation at temperatures above $600^{\circ} \mathrm{C}$. One of the alternatives to overcome this drawback is the use of antioxidants. Among them, aluminum powder has shown good results in carbon containing refractory bricks. However, its application in refractory castables is restricted by the strong tendency of aluminum powder to react with water. Some surface treatments, based on Sol-Gel process, have been employed to generate an oxide coating in order to inhibit the hydration reaction when aluminum is exposed to water. However, the efficiency of these coatings has not been examined yet in refractory castables. The present research aimed to evaluate the efficiency of $\mathrm{SiO}_{2}$ or $\mathrm{TiO}_{2}$ based coatings on inhibiting the aluminum-water reaction when added to high-carbon-containing refractory castables. These coatings were generated by metallic alkoxides or a reactive polymer, both using the Sol-Gel technique.

Keywords: refractory castables, carbon, aluminum powder, hydration, coatings.

\section{INTRODUÇÃO}

O desenvolvimento de técnicas capazes de contornar o problema da baixa molhabilidade do carbono (grafite ou coque) em água tem ampliado a utilização de concretos refratários contendo este material como revestimento para canais de corrida de alto-fornos e carros-torpedo [1,2]. A incorporação de carbono contribui para a melhoria das propriedades termomecânicas e aumento da resistência ao ataque por escória e metal fundido, prolongando a vida útil desses materiais.

Apesar dos benefícios obtidos, a adição de elevados teores de carbono ( $4 \%$ em peso) ao concreto refratário se depara com o problema de sua alta susceptibilidade à oxidação a temperaturas superiores a $600{ }^{\circ} \mathrm{C}$ [1]. A oxidação do carbono promove um aumento de porosidade do concreto e, conseqüentemente, causa uma diminuição da resistência mecânica e resistência à penetração de escória e metal fundido.
Uma das alternativas empregada na tentativa de controlar a oxidação do carbono em refratários é o uso de substâncias conhecidas como antioxidantes, que reagem preferencialmente com o carbono, diminuindo sua taxa de oxidação. Os principais antioxidantes utilizados em refratários são pós metálicos (Al, $\mathrm{Mg}$ ou Si) ou uma combinação destes. Compostos covalentes como $\mathrm{SiC}$ e $\mathrm{B}_{4} \mathrm{C}$ também têm sido utilizados com o mesmo propósito [1,3]. Dentre eles, o pó de alumínio tem mostrado bons resultados quando incorporado à composição de peças prensadas. No entanto, sua utilização em concretos refratários é limitada pela forte tendência que apresenta em se hidratar, gerando gás hidrogênio [4, 5]. Isto apresenta, na prática, uma série de restrições operacionais devido ao risco de acúmulo e explosão do gás gerado. Além disso, com a hidratação, as partículas de alumínio perdem sua eficiência como antioxidante devido à formação de outros compostos, tais como alumina gel, boemita $(\mathrm{AlOOH})$ e baierita ou gibsita $\left[\mathrm{Al}(\mathrm{OH})_{3}\right][6]$. 


$$
\begin{aligned}
& 2 \mathrm{Al}+3 \mathrm{H}_{2} \mathrm{O} \rightarrow \mathrm{Al}_{2} \mathrm{O}_{3 \text { gel }}+3 \mathrm{H}_{2}, \\
& \mathrm{Al}+2 \mathrm{H}_{2} \mathrm{O} \rightarrow \mathrm{AlOOH}+3 /{ }_{2} \mathrm{H}_{2}, \\
& \mathrm{Al}+3 \mathrm{H}_{2} \mathrm{O} \rightarrow \mathrm{Al}(\mathrm{OH})_{3}+3 /{ }_{2} \mathrm{H}_{2} .
\end{aligned}
$$

Na tentativa de viabilizar o uso do pó de alumínio como antioxidante em concretos refratários contendo carbono, algumas técnicas de recobrimento têm sido empregadas como forma de inibir sua hidratação. Tratamentos superficiais baseados na técnica de Sol-Gel, que utilizam alcóxidos metálicos como precursores para obtenção de um recobrimento à base de óxido $\left(\mathrm{SiO}_{2}, \mathrm{Al}_{2} \mathrm{O}_{3}\right.$ e $\mathrm{TiO}_{2}$ ), têm se mostrado uma alternativa para inibir a reação do pó de alumínio com a água $[7,8]$.

Apesar destes avanços, pouco se encontra na literatura científica a respeito da eficiência desses recobrimentos quando o pó de alumínio recoberto é adicionado ao concreto refratário. A maioria dos estudos relata apenas a avaliação dos recobrimentos quando o pó de alumínio recoberto é exposto diretamente à água $[7,8]$. Considerando que outras variáveis (cisalhamento entre as partículas durante a mistura, meio químico, $\mathrm{pH}$, dentre outras) podem atuar sobre o pó recoberto quando adicionado ao concreto, é importante que a eficiência destes recobrimentos seja avaliada em condições mais próximas da aplicação.

Outro ponto importante a ser considerado diz respeito à metodologia que vem sendo empregada para avaliar a hidratação do pó de alumínio [7-9]. As técnicas até então utilizadas (MEV e DRX) limitam a quantidade de material a ser analisado e permitem a detecção das fases formadas como resultado da hidratação apenas quando padrões internos são empregados. Uma vez que algumas das fases geradas podem apresentar uma natureza amorfa, verifica-se a complexidade da metodologia proposta para avaliar a hidratação do alumínio.

No presente trabalho, utilizou-se a técnica de Sol-Gel para a produção de recobrimentos à base de $\mathrm{SiO}_{2}$ ou $\mathrm{TiO}_{2}$ sobre as partículas de alumínio. A tendência à hidratação do pó de alumínio recoberto foi avaliada diretamente em concretos refratários fazendo uso de uma técnica capaz de detectar a liberação de gás hidrogênio $\left(\mathrm{H}_{2}\right)$ como produto da reação do alumínio com a água [5].

\section{MATERIAIS E MÉTODOS}

Neste trabalho, utilizou-se o pó de alumínio 101 produzido pela Alcoa-Brasil. As especificações gerais deste material se encontram na Tabela I.

O pó de alumínio como recebido foi submetido a diferentes tratamentos fazendo uso do método Sol-Gel. Os alcóxidos metálicos utilizados foram o silano tetraetóxido de silício (TEOS, $\mathrm{Si}\left(\mathrm{OC}_{2} \mathrm{H}_{5}\right)_{4}$, Merck), o organosilano n-octiltrietoxisilano (Z-6341, $\left[\mathrm{Si}\left(\mathrm{CH}_{3}\left(\mathrm{CH}_{2}\right)_{7}\right)\left(\mathrm{OC}_{2} \mathrm{H}_{5}\right)_{3}\right]$, Dow Corning) e os titanatos tetra-2-etil-hexil de titânio (Tyzor TOT, [Ti $\left.\left(\mathrm{OCH}_{2} \mathrm{CH}\left(\mathrm{C}_{2} \mathrm{H}_{5}\right) \mathrm{C}_{4} \mathrm{H}_{9}\right)_{4}\right]$, DuPont $)$ e quelato acetilacetonato de titânio (Tyzor ETHAA, [Ti( $\left.\left(\mathrm{CH}_{3} \mathrm{COCHCOCH}_{3}\right)_{2}(\mathrm{RO})_{2}\right]$, DuPont). Utilizou-se, também, um polímero reativo (metilhidrogênio siloxano, Dow Corning), o qual consiste de um silicone formado por cadeias lineares de átomos de silício e oxigênio alternados ( $\mathrm{Si}-\mathrm{O}-\mathrm{Si}$, grupos siloxanos) com grupos metila ligados aos átomos de silício.

O tratamento com TEOS consistiu na adição de pó de Al como recebido a uma solução contendo este silano, etanol (pureza: 99,5\% vol., Synth) e água destilada com razão molar 1:4:4. Após 20 minutos de mistura, o pó de Al recoberto foi separado por centrifugação e seco em estufa a $100{ }^{\circ} \mathrm{C}$, como descrito na literatura [7]. O tratamento com os demais alcóxidos metálicos (Z-6341, TOT e ETHAA) e o polímero reativo consistiu na adição de pó de $\mathrm{Al}$ como recebido a uma solução contendo o alcóxido (ou polímero reativo) e hexano com razão 1:50 em volume. Após 20 minutos de mistura, o solvente foi evaporado com o auxílio de uma placa de aquecimento e o pó de Al colocado em estufa a $60{ }^{\circ} \mathrm{C}$, seguindo sugestões dos fabricantes. Acredita-se que, a partir destes tratamentos, uma camada não-cristalina de $\mathrm{SiO}_{2}$ (TEOS, Z-6341 e Polímero Reativo) ou $\mathrm{TiO}_{2}$ (TOT e ETHAA) tenha sido formada na superfície das partículas de alumínio.

A tendência à hidratação do pó de alumínio como recebido [Al sem tratamento (Al st)] e após tratamento com TEOS, Z-6341, Polímero Reativo, TOT e ETHAA foi avaliada através de ensaios a $50{ }^{\circ} \mathrm{C}$, em água e no concreto. O concreto refratário empregado trata-se de uma composição UBTC (Ultra-baixoteor de cimento) no sistema $\mathrm{Al}_{2} \mathrm{O}_{3}-\mathrm{SiC}-\mathrm{SiO}_{2}-\mathrm{C}$ (Tabela II) elaborada segundo o modelo de distribuição de partículas de Andreasen, com coeficiente (q) igual a 0,21. Foram utilizados Polimetacrilato de Sódio (Darvan-7S, Vanderbilt - teor: 0,97 $\mathrm{mg} / \mathrm{m}^{2}$ ) como dispersante e um surfactante não-iônico (HLB 8 - teor: $4 \mathrm{mg} / \mathrm{m}^{2}$ ) para promover a molhabilidade e dispersão das partículas de carbono no concreto [2]. Um teor de $0,3 \%$-p de pó de alumínio (como recebido ou recoberto) foi adicionado à composição a seco, antes da adição de água ao concreto. Nos ensaios em água, as quantidades de pó de $\mathrm{Al}$ e $\mathrm{H}_{2} \mathrm{O}$ utilizadas foram proporcionais à relação entre estes materiais presentes no concreto.

\begin{tabular}{|c|c|c|c|c|c|}
\hline \multicolumn{3}{|c|}{ Análise Granulométrica (\%) } & \multicolumn{3}{|c|}{ Análise Química (\%) } \\
\hline & & & Elementos Químicos & Típico & Máx. \\
\hline \multirow[t]{2}{*}{+100 mesh } & \multirow[t]{2}{*}{+200 mesh } & \multirow[t]{2}{*}{-325 mesh } & $\overline{\mathrm{Al}}$ & 99,70 & - \\
\hline & & & $\mathrm{Fe}$ & 0,15 & 0,25 \\
\hline \multirow[t]{2}{*}{ máx. 0,2 } & \multirow[t]{2}{*}{$10,0-25,0$} & \multirow[t]{2}{*}{$75,0-90,0$} & $\mathrm{Si}$ & 0,07 & 0,15 \\
\hline & & & Outros, total & - & 0,15 \\
\hline
\end{tabular}

Tabela I - Especificação do pó de alumínio.

[Table I - As-received aluminum powder characteristics.] 
Tabela II: Composição de concreto refratário UBTC no sistema $\mathrm{Al}_{2} \mathrm{O}_{3}-\mathrm{SiC}-\mathrm{SiO}_{2}-\mathrm{C}$. [Table II: High-carbon-containing refractory castable formulation $\left(\mathrm{Al}_{2} \mathrm{O}_{3}-\mathrm{SiC}-\mathrm{SiO}_{2}-\mathrm{C}\right)$.]

\begin{tabular}{|c|c|c|}
\hline & Matérias Primas & $\%$ - peso \\
\hline \multirow[t]{4}{*}{ Agregados } & Alumina Eletrofundida Branca (EK8R, malha 5/16 - 200) & 53,5 \\
\hline & SiC (EC6R, malha 6 - 200) & 17,5 \\
\hline & Alumina Calcinada A-3000 $\mathrm{FL}^{\triangle}$ & 11,0 \\
\hline & Cimento $(\mathrm{CA}-270)^{\triangle}$ & 3,0 \\
\hline \multirow[t]{3}{*}{ Matriz } & Microssílaca $(971-D)^{\wedge}$ & 5,0 \\
\hline & Coque (Unicarbo 50) ${ }^{*}$ & 10,0 \\
\hline & Água Destilada & 6,5 \\
\hline
\end{tabular}

${ }^{\square}$ Alcoa Alumínio (Brasil); ${ }^{\circ}$ Alcoa Chemicals (EUA); `Elkem Refractories (Noruega); *Unimetal (Brasil).

Os concretos refratários $(\sim 500 \mathrm{~g})$ bem como as suspensões aquosas ( $26 \mathrm{~g}$ água destilada $+1,2 \mathrm{~g}$ pó de $\mathrm{Al}$ ) foram colocadas em um recipiente plástico dentro de um reator de aço inox com sistema de vedação adequado para evitar o vazamento de gás. Este reator foi imerso em um banho térmico à temperatura constante $\left(50^{\circ} \mathrm{C}\right)$, sendo conectado a um transdutor a partir do qual foram coletadas as medidas de pressão do hidrogênio gerado ao longo do experimento [5].

A tendência à hidratação também foi avaliada em função do método de incorporação do pó de $\mathrm{Al}$ recoberto ao concreto, dos constituintes do concreto e do tipo de ligante hidráulico utilizado. A influência do método de incorporação foi avaliada através da adição de pós recobertos (TEOS, Z-6341 e Polímero Reativo) à composição a seco (antes da adição de água) ou após o ponto de virada [10] do concreto. O efeito dos constituintes do concreto foi avaliado através da remoção do cimento CA-270, do dispersante Darvan-7S ou do surfactante de concretos refratários preparados com pó de alumínio recoberto com organosilano (Z-6341).

A influência da presença e do tipo de ligante utilizado sobre a tendência à hidratação de pós não recobertos $(\mathrm{Al} \mathrm{st})$ e recobertos com organosilano (Z-6341) foi investigada através de concretos refratários preparados sem ligante (referência), com cimento CA-270 (3,0\%-p), AlphaBond (3,0\%-p, Alcoa Chemicals, EUA) ou Sílica Coloidal (teor: 13,3\%-p, concentração: $30 \%-p$, BASF, Alemanha). No caso dos concretos preparados com Sílica Coloidal, o teor de ligante empregado já continha a quantidade de água $(6,5 \%$-p) necessária para atribuir fluidez ao concreto.

\section{RESULTADOS E DISCUSSÃO}

A técnica utilizada para identificar a reação de hidratação do pó de alumínio se baseia na evolução de gás hidrogênio gerado ao longo do tempo de experimento. Uma vez que os ensaios foram realizados dentro de um reator devidamente vedado, a elevação dos níveis internos de pressão foi atribuída à liberação de gás hidrogênio decorrente da reação do pó de alumínio com a água. Os ensaios foram conduzidos a temperatura de $50^{\circ} \mathrm{C}$, pois nessa condição a reação de hidratação do alumínio é significativamente acelerada [5].

A tendência à hidratação do pó de alumínio sem recobrimento submetido a ensaios a $50^{\circ} \mathrm{C}$ em água e concreto é apresentada na Fig. 1. Observa-se, em ambos os experimentos (curvas 3 e 4), um aumento expressivo dos níveis de pressão quando comparado aos testes realizados somente com água ou concreto sem pó de alumínio (curvas 1 e 2, respectivamente). Estes

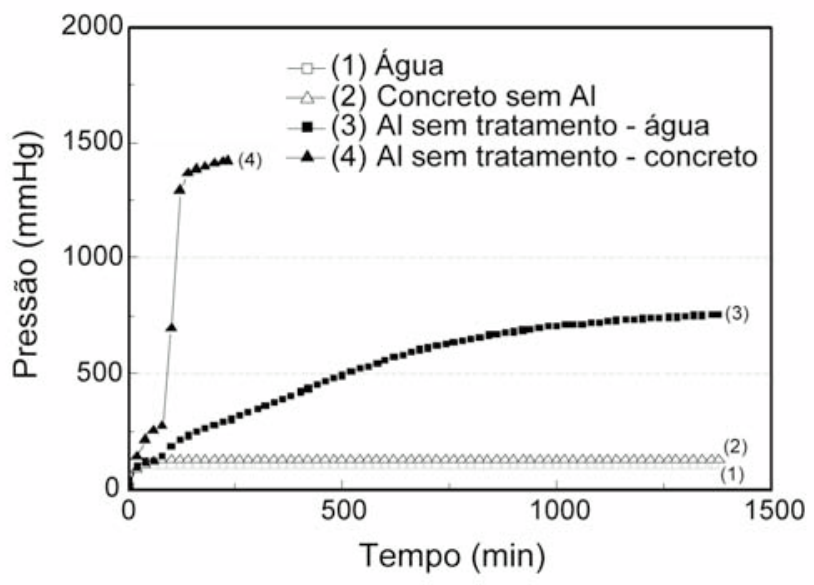

Figura 1: Tendência a hidratação do pó de alumínio sem recobrimento (como recebido) em (3) água e (4) incorporado ao concreto. São apresentadas também as curvas de referência somente com (1) água e (2) concreto sem pó de alumínio $\left(50^{\circ} \mathrm{C}\right)$.

[Figure 1: As-received aluminum powder hydration tendency (50 ${ }^{\circ} \mathrm{C}$ ) in (3) water and (4) in the refractory castable. It is also presented the reference curves for (1) plain water and (2) aluminum free refractory castable.]

resultados ilustram a eficiência da técnica em identificar a liberação do produto $\left(\mathrm{H}_{2}\right)$ da reação de hidratação do pó de alumínio.

Comparando os resultados obtidos nos ensaios em água e concreto (Fig. 1), observa-se que a reação de hidratação do pó de alumínio ocorre de maneira mais rápida e intensa quando incorporado ao concreto. Uma das possíveis explicações para este comportamento estaria relacionada com a presença de cimento nos concretos refratários. De acordo com um modelo recentemente proposto na literatura, a reação do pó de alumínio 
com a água em concretos contendo cimento seria controlada, principalmente, pela taxa de dissolução da camada protetora de hidróxido de alumínio formada ao redor das partículas de Al como resultado das reações (A), (B) e (C) [6].

Segundo este modelo, a dissolução da camada de hidróxido de alumínio seria afetada, sobretudo, por dois fatores: (1) o aumento de $\mathrm{pH}$ do sistema e (2) o efeito do íon comum $\left(\mathrm{Al}(\mathrm{OH})_{4}^{-}\right)$existente entre o produto da dissolução da camada protetora e o processo de dissociação/precipitação dos íons constituintes do cimento [6]. Em contato com a água, o cimento sofre dissociação de seus íons $\left(\mathrm{Ca}^{2+} \mathrm{e} \mathrm{Al}(\mathrm{OH})_{4}^{-}\right)$promovendo um aumento da concentração destes no meio aquoso e a elevação do $\mathrm{pH}$ do concreto para condições altamente alcalinas $(12<\mathrm{pH}<12,5)$ [11]. Nessas condições extremas de $\mathrm{pH}$, a camada protetora de hidróxido de alumínio é continuamente dissolvida, contribuindo para saturar o meio com íons $\mathrm{Al}(\mathrm{OH})_{4(\mathrm{aq})}^{-}$. Quando o grau de saturação do sistema é atingido, ocorre a precipitação dos íons $\mathrm{Ca}^{2+}$ e $\mathrm{Al}(\mathrm{OH})_{4}^{-}$na forma de núcleos de aluminato de cálcio hidratados. Conseqüentemente, a dissolução da camada protetora é acelerada em função da diminuição da concentração de íons

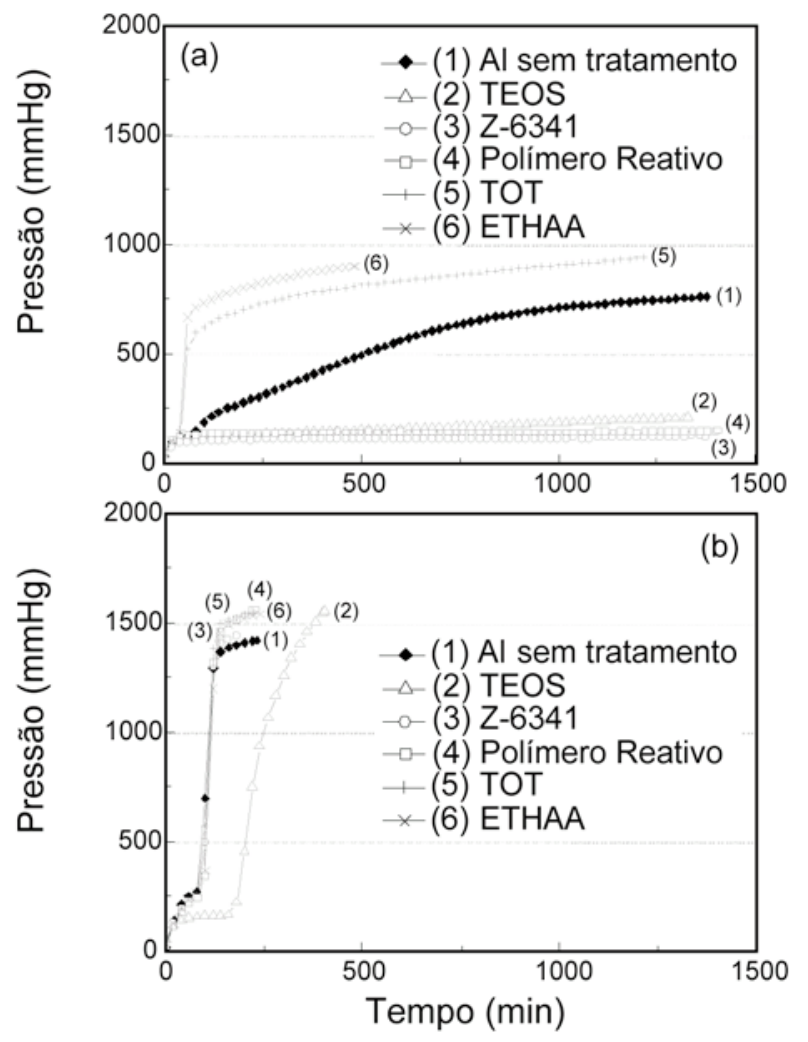

Figura 2: Eficiência dos recobrimentos a base de $\mathrm{SiO}_{2}$ (TEOS, Z6341 e Polímero Reativo) e $\mathrm{TiO}_{2}$ (TOT e ETHAA) em inibir a reação de hidratação do pó de alumínio quando submetidos a ensaios a $50{ }^{\circ} \mathrm{C}$ em (a) água e (b) concreto refratário, comparativamente ao pó de alumínio sem tratamento.

[Figure 2: Efficiency of the $\mathrm{SiO}_{2}$ (TEOS, Z-6341 and Reactive Polymer) and $\mathrm{TiO}_{2}$ (TOT and ETHAA) coatings to inhibit the aluminum-water reaction at $50{ }^{\circ} \mathrm{C}$ on (a) water and (b) castable hydration tests, compared to hydration behavior of the as-received aluminum powder (uncoated Al).]
$\mathrm{Al}(\mathrm{OH})_{4}^{-}$no meio aquoso, deixando desprotegida a superfície da partícula de Al. Dessa forma, a liberação de gás hidrogênio seria intensificada devido à contínua reação da superfície com a água.

A eficiência dos diferentes recobrimentos à base de $\mathrm{SiO}_{2} \mathrm{e}$ $\mathrm{TiO}_{2}$ em inibir a reação de hidratação do pó de alumínio em água e concreto refratário é apresentada na Fig. 2. Observa-se que, com exceção dos pós recobertos com TOT e ETHAA, todos os outros recobrimentos (TEOS, Z-6341 e Pol. Reativo) se mostraram muito eficientes em inibir a reação de hidratação do alumínio quando em água (Fig. 2a). Porém, quando incorporado ao concreto (Fig. 2b), nenhum dos recobrimentos foi capaz de impedir que o pó de alumínio reagisse com a água. A diferença observada no desempenho dos diferentes recobrimentos em água e no concreto evidencia a importância de se avaliar em condições reais de aplicação.

As razões que poderiam explicar a ineficiência dos recobrimentos à base de $\mathrm{SiO}_{2}$ no concreto foram relacionadas a dois fatores: (1) o intenso cisalhamento que as partículas estão sujeitas durante o processo de mistura, o qual poderia danificar o recobrimento, expondo a superfície das partículas de alumínio para reagir com a água; e (2) a possibilidade da camada de recobrimento ser destruída pela ação química dos constituintes do concreto, deixando desprotegida a superfície do pó de alumínio.

Os ensaios que avaliaram o efeito da mistura sobre o desempenho dos recobrimentos mostraram que a hidratação acontece independentemente do momento em que o pó de alumínio recoberto é adicionado ao concreto (Fig. 3). Verificouse que a diferença de comportamento se resume a um ligeiro aumento no tempo de início da reação para os pós recobertos adicionados após o ponto de virada do concreto [10].

A Fig. 4 ilustra os resultados obtidos nos ensaios que avaliaram o efeito dos constituintes do concreto sobre o

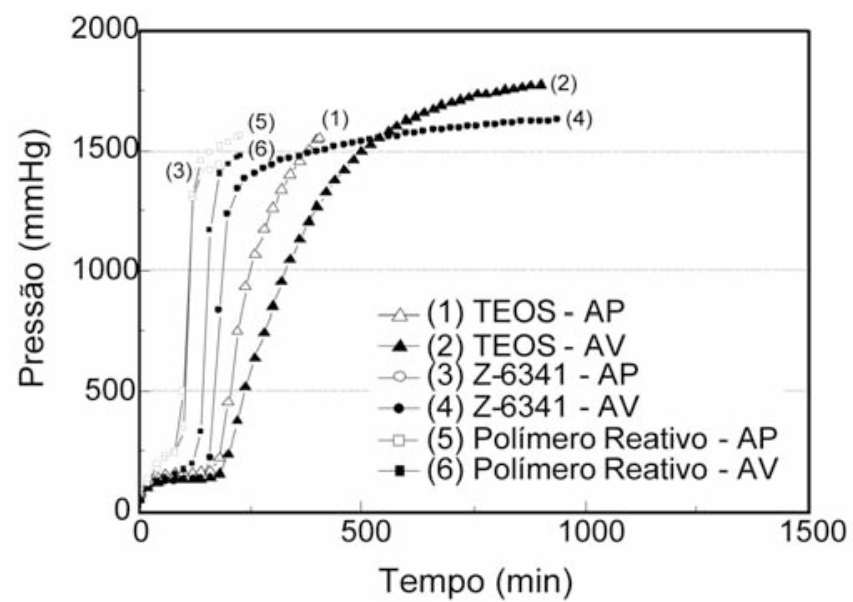

Figura 3: Efeito do método de incorporação do pó de alumínio recoberto com $\mathrm{SiO}_{2}$ (TEOS, Z-6341 e Polímero Reativo) sobre sua tendência a hidratação em concreto refratário $\left(50^{\circ} \mathrm{C}\right)$. (AP) Adição prévia do pó de $\mathrm{Al}$ recoberto à composição a seco ou (AV) após a virada do concreto.

[Figure 3: Effect of addition method on the hydration tendency of $\mathrm{SiO}_{2}$ coated Al powder (TEOS, Z-6341 and Reactive Polymer) in refractory castables $\left(50{ }^{\circ} \mathrm{C}\right)$. Coated aluminum powder addition $(A P)$ at the beginning of the mixing step or (AV) after castable turning point.] 


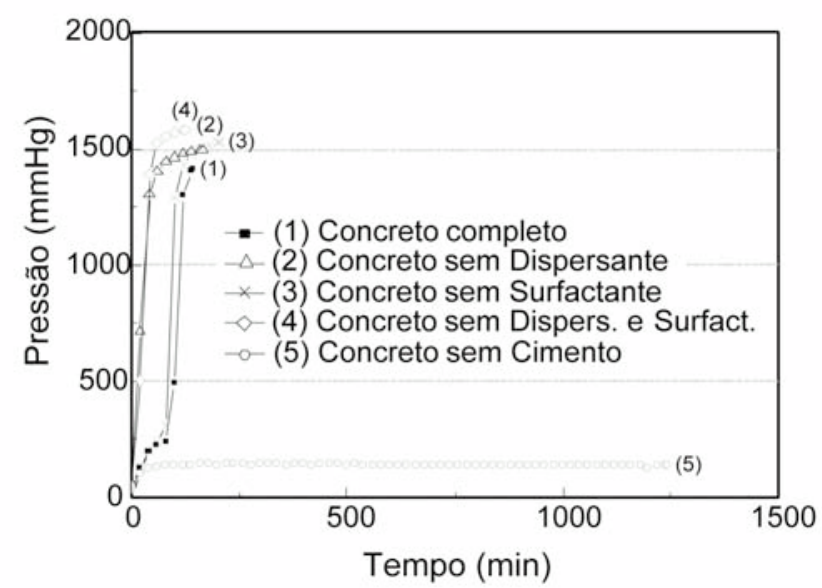

Figura 4: Influência dos constituintes do concreto (Dispersante, Surfactante e Cimento CA-270) sobre a eficiência dos recobrimentos de $\mathrm{SiO}_{2}(\mathrm{Z}-6341)$ em inibir a reação de hidratação do pó de alumínio em concretos refratários $\left(50{ }^{\circ} \mathrm{C}\right)$.

[Figure 4: Influence of the castable's constituents (Dispersant, Surfactant and Cement $\mathrm{CA}$-270) on the $\mathrm{SiO}_{2}$-coating efficiency (Z-6341) to inhibit the aluminum-water reaction in refractory castables $\left(50^{\circ} \mathrm{C}\right)$.]

desempenho dos pós recobertos com organosilano (Z-6341). Observa-se que a remoção isolada ou combinada de dispersante (Darvan-7S) e surfactante (HLB 8) não impedem que o pó de alumínio recoberto se hidrate. No entanto, quando o cimento CA-270 é removido, verifica-se que a reação de hidratação do pó de alumínio não ocorre.

Estes resultados mostram que o cimento não apenas atua no mecanismo de hidratação do pó de alumínio em concreto refratário, mas, também, exerce influência direta sobre a eficiência dos recobrimentos à base de $\mathrm{SiO}_{2}$. Como descrito anteriormente, a presença de cimento promove um aumento expressivo do $\mathrm{pH}$ do concreto [11]. Nessas condições, os recobrimentos à base de $\mathrm{SiO}_{2}$ são muito instáveis (Fig. 5) e os grupos silanóis $(\mathrm{Si}-\mathrm{OH})$ e siloxanos $(\equiv \mathrm{Si}-\mathrm{O}-\mathrm{Si} \equiv)$ reagem com o meio formando silicatos solúveis [12], deixando, assim, desprotegida a superfície da partícula de alumínio.

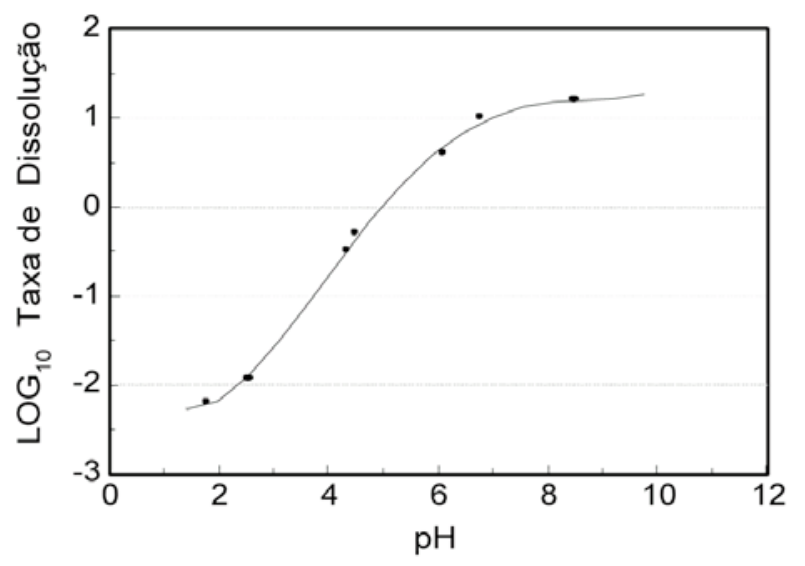

Figura 5: Taxa de dissolução da sílica em função do pH (adaptado de [13]).

[Figure 5: Silica dissolution rate vs. pH (adapted from [13]).]
Uma vez que tanto a ineficiência dos recobrimentos à base de $\mathrm{SiO}_{2}$ quanto à hidratação do pó de alumínio (sem recobrimento) em concreto foram relacionadas à presença de cimento, verificou-se a possibilidade de solucionar o problema da hidratação do $\mathrm{Al}$ substituindo o cimento por um outro ligante que não promovesse um aumento de $\mathrm{pH}$ para condições críticas aos recobrimentos, ou mesmo, não proporcionasse o efeito do íon comum $\left(\mathrm{Al}(\mathrm{OH})_{4}^{-}\right)$descrito anteriormente.

Neste sentido, foram realizados ensaios em concreto substituindo o cimento CA-270 por AlphaBond ou Sílica Coloidal. Os resultados mostraram que apesar do $\mathrm{pH}$ do concreto ter sido reduzido para valores próximos a 9 com a utilização de AlphaBond, estas condições ainda se mostram críticas para os recobrimentos à base de sílica e a reação de hidratação veio a ocorrer (Fig. 6). Além disso, devido ao fato do AlphaBond ser uma Alumina $\rho$, obtida a partir da calcinação do $\mathrm{Al}(\mathrm{OH})_{3}$ a 700 $800^{\circ} \mathrm{C}$, supõe-se que o efeito do íon comum $\left(\mathrm{Al}(\mathrm{OH})_{4}^{-}\right)$também esteja atuando sobre o sistema, contribuindo para acelerar a reação do pó de alumínio com a água.

Quando o cimento CA-270 é substituído por Sílica Coloidal, observa-se que reação de hidratação não acontece tanto com o pó de alumínio recoberto (Z-6341) quanto com o pó não recoberto. Considerando que a utilização de Sílica Coloidal também reduziu o $\mathrm{pH}$ do concreto para valores semelhantes aos obtidos com o emprego de AlphaBond ( $\mathrm{pH} \sim 9$ ), verifica-se que o uso de um ligante cujo processo de

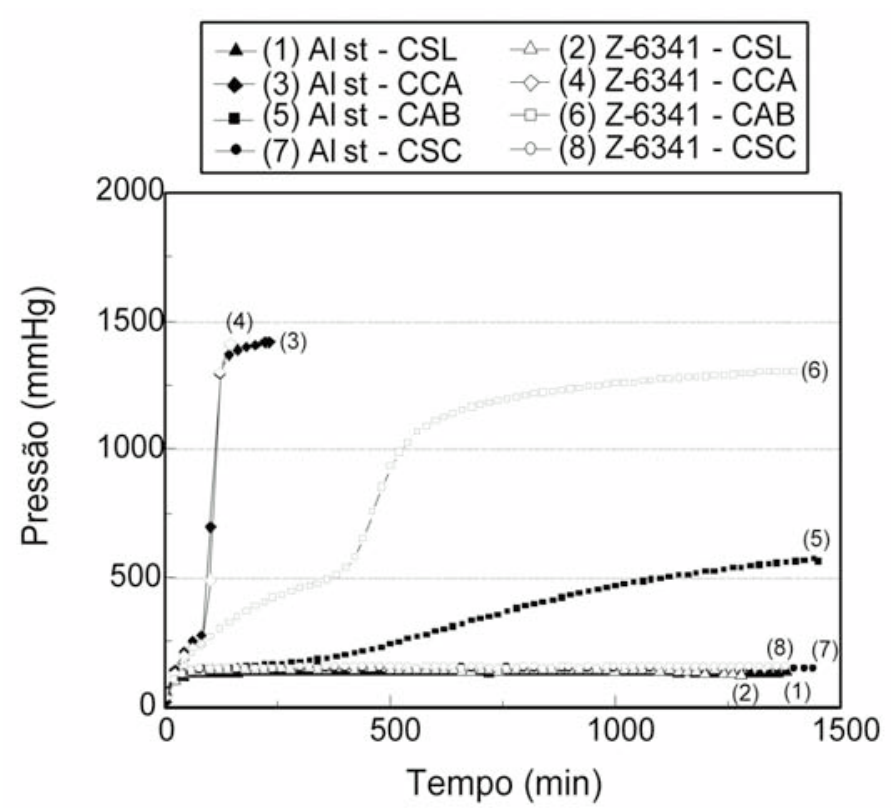

Figura 6: Efeito da presença e tipo de ligante utilizado sobre a tendência a hidratação do pó de alumínio sem recobrimento (Al st) e recoberto (Z-6341) em concreto refratário $\left(50^{\circ} \mathrm{C}\right)$. (CSL: Concretos sem Ligante; CCA: Concretos com CA-270; CAB: Concretos com AlphaBond e; CSC: Concretos com Sílica Coloidal).

[Figure 6: Effect of distinct binders on coated (Z-6341) and uncoated (as-received: Al st) aluminum powder hydration tendency in refractory castables $\left(50^{\circ} \mathrm{C}\right)$. (CSL: Binder free castables; $C C A$ : Cement CA-270 containing castables; CAB: AlphaBond containing castables and; CSC: Colloidal Silica containing castables).] 
consolidação não apresente o efeito do íon comum $\left(\mathrm{Al}(\mathrm{OH})_{4}^{-}\right)$ proporciona condições para que a reação de hidratação do pó de alumínio em concretos não aconteça. Este argumento ainda é sustentado pelos resultados obtidos a partir de um concreto preparado sem cimento CA-270 e com pó de alumínio sem recobrimento (Fig. 6, curva 1), onde a reação de hidratação também não foi verificada.

Resultados como estes sugerem que as condições de $\mathrm{pH}$ do concreto e, principalmente, a presença de um íon comum $\left(\mathrm{Al}(\mathrm{OH})_{4}^{-}\right)$, resultante da dissolução da camada protetora e do processo de dissociação/precipitação de ligantes aluminosos, desempenham um papel relevante tanto no comportamento dos recobrimentos à base de $\mathrm{SiO}_{2}$ quanto na reação do pó de alumínio com a água em concretos refratários. Adicionalmente, torna-se viável a possibilidade de empregar o pó de alumínio como antioxidante em concretos refratários contendo carbono sem a necessidade de recobri-lo.

Embora os resultados tenham sido expressivos, será ainda necessário averiguar: (1) qual a quantidade de pó de Al a ser utilizada para inibir a oxidação dos concretos contendo, por exemplo, 10\%-p de carbono; (2) qual o efeito de um provável aumento no teor de pó de $\mathrm{Al}$ empregado sobre a reologia dos concretos refratários.

\section{CONCLUSÕES}

A técnica empregada neste trabalho se mostrou capaz de avaliar a tendência à hidratação do pó de alumínio, permitindo, também, verificar a eficiência de diferentes recobrimentos em inibir a hidratação do alumínio tanto em água quanto em um concreto refratário contendo alto teor de carbono.

A reação de hidratação do pó de alumínio sem tratamento superficial no concreto, além de mais intensa, ocorre em tempos menores aos observados nos ensaios em água. Tal comportamento foi relacionado, principalmente, ao aumento de $\mathrm{pH}$ e ao efeito do íon comum, ambos decorrentes da presença cimento aluminoso nos concretos refratários.

Os recobrimentos obtidos com alcóxidos de Ti não conseguiram impedir a hidratação do pó de alumínio tanto em água quanto no concreto. Já os recobrimentos preparados com alcóxidos de Si inibiram a hidratação do alumínio em água, porém, quando adicionados ao concreto, estes recobrimentos não impediram a reação de hidratação.

A ineficiência dos recobrimentos à base de $\mathrm{SiO}_{2}$ em concreto foi atribuída ao aumento de $\mathrm{pH}$ decorrente da dissociação do cimento presente. Substituindo o cimento utilizado por Sílica Coloidal, verificou-se que a reação de hidratação tanto do pó de alumínio recoberto quanto sem recobrimento foi inibida em concretos refratários contendo carbono.

\section{AGRADECIMENTOS}

Os autores agradecem a FAPESP e ao CNPq pelo suporte oferecido e a Alcoa Alumínio S/A, Unimetal e BASF (Alemanha) pelo material gentilmente cedido.

\section{REFERÊNCIAS}

[1] S. Zhang, W. E. Lee, "Carbon-Containing Castables: current status and future prospects", British Ceramic Transactions 101, 1 (2002)1-8.

[2] I. R. de Oliveira, A. R. Studart, R. Salomão, V. C. Pandolfelli, "High-Carbon-Containing Refractory Castables", Am. Ceram. Soc. Bull. 82, 10 (2003) 951-958.

[3] M. Rigaud, "New additives in carbon-bonded refractories", Ceramics: charting the future. Advances in Science and Technology, P. Vinvenzini, Tchna Srl, 1995, pp. 399-413.

[4] H. Yaoi, N. Tsutsui, T. Suzuki, "Development of nonaluminum monolithic refractories for BF through", Taikabutsu Overseas 14, 3, (1994) 26-33.

[5] M. D. M. Innocentini, L. A. Nascimento, A. E. M. Paiva, V. C. Pandolfelli, B.A. Menegazzo, L.R.M. Bittencourt, "Aluminum-Containing Refractory Castables: Part 1, Evaluation of Hydrogen-Gas Generation", Am. Ceram. Soc. Bull. 82, 6 (2003) 45-51.

[6] A. Studart, M. D. M. Innocentini, I. R. de Oliveira, V. C. Pandolfelli, "Reaction of Aluminum Powder with water in cement-containing refractory castables", artigo submetido à publicação no J. Eur. Ceram. Soc. (2004).

[7] S. Zhang, S. Hashimoto, W. E. Lee, "Inhibiting Hydration of Aluminum Powder Using $\mathrm{SiO}_{2}$ Coatings", Refractory Application and News 8, 3 (2003) 21-25.

[8] S. Zhang, W. E. Lee, "Development of Carbon-Containing Castables", Proceedings of the Unified International Technical Conference on Refractories - UNITECR' 03, Osaka, Japão. (2003), pp. 543-545.

[9] S. Zhang, S. Hashimoto, W. E. Lee, "Effect of Magnesia and Calcium Aluminate Cement on the Hydration of Aluminum Powder in Castables Matrix", Proceedings of the Unified International Technical Conference on Refractories - UNITECR' 03, Osaka, Japão. (2003), pp. 643-646.

[10] R. G. Pileggi, A. R. Studart, V. C. Pandolfelli, J. Gallo, "How Mixing Affects the Rheology of Refractory Castables, Part 1", Am. Ceram. Soc. Bull. 80, 6 (2001) 27-31.

[11] P. P. Barret, D. Ménétrier, D. Bertrandie, "Contribution to the study of the kinetic mechanism of aluminous cement setting, I - Latent Periods in Heterogeneous and Homogeneous Milieus and the Absence of Heterogeneous Nucleation", Cement and Concrete Research 4 (1974) 545556.

[12] E. Tonhi, K. E. Collins, I. C. S. Jardim, C. H. Collins, "Fases Estacionárias para Cromatografia Líquida de Alta Eficiência em Fase Reversa (CLAE-FR) Baseadas em Superfícies de Óxidos Inorgânicos Funcionalizados", Quim. Nova, 25, 4 (2002) 616-623.

[13] Disponível na base de dados http://www.psrc.usm.edu/ mauritz/solgel.html, acessada no dia 25/01/2004.

(Rec. 26/01/04, Ac. 05/03/04) 